\title{
AN INVESTIGATION INTO CONTRACTORS' EVALUATION OF RISKS ASSOCIATED WITH THE JBCC PRINCIPAL BUILDING AGREEMENT IN SOUTH AFRICA
}

\author{
Ayman Othman ${ }^{1}$ and Nishani Harinarain ${ }^{2}$ \\ ${ }^{1}$ Architectural Engineering Department, The British University in Egypt (BUE), El Sherouk City, Postal No. \\ 11837 - P.O. Box 43, Cairo, Egypt, Tel. (+202) 26890000, Fax. (+202) 26875889/97, \\ Email: ayman.othman@bue.edu.eg; aaeothman@gmail.com* \\ ${ }^{2}$ School of Civil Engineering, Surveying and Construction, University of KwaZulu-Natal, King George V \\ Avenue, Durban 4041, South Africa, Tel: +27 (031) 260 1206, fax: +27 (031) 2601411, \\ E-mail:harinarain@ukzn.ac.za
}

\begin{abstract}
Construction is a risky business, and risk management is an essential responsibility in managing construction projects and organisations. Hence, construction contracts have been developed to organise the relationship between project participants and manage associated risks. This paper provides an investigation into the contractors' responses and feedback obtained through the application of an innovative framework developed by the authors towards identifying, quantifying and classifying the risks associated with the Joint Building Contractors Committee Principal Building Agreement Series 2000 (JBCC PBA) in South Africa. Qualitative and quantitative techniques have been used in this study for data collection and analysis. Purposive sampling was adopted to identify the respondents, and 9 construction managers were interviewed. The interviews were structured so that they were carried out in a free and unbiased manner and responding contractors were asked to complete a questionnaire. Analysis of responses showed that the developed Identification, Quantification and Classification Framework (IQCF) is an innovative and accepted tool that is able to fill the gap in managing project risks and will complement current practices. It is seen to be of benefit to firms in assisting with training of employees and helping junior employees understands and uses the JBCC (PBA). Investigating the validity and reliability of the developed framework is of prime importance to ensure its suitability to manage risks associated with the JBCC (PBA). For this reason contractor's responses and feedback are based on the practical application of the framework which ultimately increases its value and contribution to the construction industry. The adoption and application of the framework will enable contractors to enhance the risk-management process in South Africa.
\end{abstract}

Keywords: contractors, JBCC (PBA), Identification, Quantification and Classification Framework (IQCF), risk management, South Africa 
JCPMI Vol. 1 (1): 1 - 26, (November) 2012

\section{INTRODUCTION}

The construction industry is subject to more risk and uncertainty than many other industries. This is because the process of taking a project from initial investment appraisal to completion and into use is complex and entails time-consuming design and production processes. It requires a multitude of people with different skills and interests and the co-ordination of a wide range of disparate, yet interrelated, activities. Such complexity is also compounded by many external and uncontrollable factors (Edwards and Bowen, 2005; Flanagan and Norman, 1993).

Being one of the biggest industries worldwide, there are hundreds of contracts signed every day (Sawczuk, 1996) and as soon as two parties, the employer and the contractor, have signed a contract they have taken risks on board. Their awareness of the risk, and the steps they have taken to minimise their share of the risk, will determine the likelihood of a problem occurring. Clough (1975) stated that contract articles have to be read carefully by all parties to the contract before signing the contract to avoid any disputes and conflicts during the execution of the contract

Risks need to be identified, analysed and apportioned much more openly and professionally. The nature of the risk and its perception by the role-players in the construction industry determines how it is treated or managed (Edwards and Bowen, 2005). Contractors have to be aware of their obligations and the risks associated with their contracts (Smith, 1998). A framework was developed by the authors to identify, quantify and classify risks associated with the Joint Building Contractors Committee Principal Building Agreement Series 2000 (JBCC PBA) (Othman and Harinarain, 2009). In order to evaluate the developed framework and ensure its validity and reliability, this paper analyses the responses and feedback gained from contractors through the application of developed framework.

\section{PURPOSE OF THE PAPER}

This paper aims to investigate the responses and feedback obtained from contractors through the application of the framework developed by the authors and introduced to the industry to enable contractors to identify, quantify and classify the risks associated with the Joint Building Contractors Committee Principal Building Agreement Series 2000 (JBCC PBA) in South Africa.

\section{EVALUATION OF THE IDENTIFICATION, QUANTIFICATION AND CLASSIFICATION FRAMEWORK}

In order to ensure that the developed framework is valid and reliable, it has to be evaluated. Evaluation is used to appraise the whole value of the framework. Verification and validation are formal methods for testing a computer programme or framework. Verification is the process of 
JCPMI Vol. 1 (1): 1 - 26, (November) 2012

ensuring that the framework does not contain any technical errors, i.e. by ensuring that the framework has been formulated correctly. Validation is the process which determines whether or not the framework meets the required specification and is suitable for its intended purpose, thereby ensuring that the framework has been formulated in the intended manner (Miles et al., 2000). In other words, verification assures that 'you built it right' and validation assures that 'you built the right thing'. Three basic questions for framework verification and validation have to be asked:

(1) What to evaluate?

(2) How to evaluate?

(3) When to evaluate? (Ng and Smith, 1998)

\section{What to evaluate?}

The aim of evaluating the Identification, Quantification and Classification Framework (IQCF) was to determine how well the developed system had achieved its objectives. This was achieved by assessing how well the developed framework enabled contractors to:

a. Identify risks associated with the JBCC (PBA) - Edition 5.0

b. Quantify risks associated with the JBCC (PBA) - Edition 5.0

c. Classify risks associated with the JBCC (PBA) - Edition 5.0

d. Encourage contractors to write down their comments, feedback and suggestions to improve the developed framework

\section{How to evaluate?}

Generally, two methods are used for evaluating frameworks. In the first method, users are provided with a working version of the framework under evaluation and allowed to make use of it over a prolonged time period. This method gives evaluators an opportunity to get used to the framework and form an opinion on whether the stated benefits are actually achieved. On the other hand, this is not an easy task as there are many difficulties which are magnified when the trial framework must be integrated with existing systems. A different approach (Method 2) is followed when a relatively large number of evaluators are available for a short period of time. An evaluation session is held in a single location with all the evaluators participating simultaneously. The session comprises a handson usage portion, where the evaluators are guided through a usage scenario with the use of appropriate notes. This is followed by the distribution and completion of a questionnaire by each evaluator (Miles et al., 2000; Ren, 2002). During the course of evaluating the IQCF in this study, the second method was adopted. In this approach, the major characteristics of the IQCF, its development process, and the use of the framework were explained to the evaluation groups. Feedback and suggestions were obtained during a number of interviews carried out with a representative and non-

biased sample of contractors who were asked to respond to the survey questions in an evaluation questionnaire. 
JCPMI Vol. 1 (1): 1 - 26, (November) 2012

\section{When to evaluate?}

The development of the IQCF was done in an iterative process. Regular revision and evaluation of the developed framework was carried out by the authors with the collaboration of contractors to assess how well the developed framework covered the requirements to identify, quantify and classify the risks associated with the JBCC (PBA). When a satisfactory version was produced, it was applied by means of a series of interviews carried out with a selected sample of contractors. During each interview, the participants were asked to fill out a questionnaire and thereafter data were arranged in a tabulated format designed by the authors to evaluate the suggested framework. Evaluators' comments and suggestions were considered and applied to enhance the performance of the designed framework.

\section{BUILDING PROCUREMENT AND CONSTRUCTION CONTRACTS}

\section{Definitions and responsibilities}

The term 'procurement' when used in a building context could be defined as the overall process of acquiring a building. When a client wishes to renovate, extend or construct a new building he/she will normally need the services of many construction-related organisations to achieve the desired end-product. A number of procurement methods may be used by a client to acquire these services. These procurement methods give the client a choice of various management structures, different contractual arrangements and varying degrees of client risk.

\section{Traditional methods}

a. Based on firm bills of quantities

b. Based on bills of approximate quantities

c. Based on drawings and specifications

d. Based on a schedule of rates

e. Based on cost reimbursements

\section{Alternative methods}

a. Design and build

b. Management fee (Cartlidge, 2009)

A contract is defined as an agreement between two parties, one of whom, the building contractor, agrees to erect a building, and the other, the employer, agrees to pay for it. Personal rights and obligations are created by the agreement, and the right of one party is the obligation of the other. A contract comes into existence on the acceptance of an offer. There is a meeting of minds, a consensus 
JCPMI Vol. 1 (1): 1 - 26, (November) 2012

that is an essential element of a contract (Finsen, 1999). The purpose of the contract is to establish the rights, duties, obligations, and responsibilities of the various contracting parties in order to allocate risk. A building contract is a trade-off between the contractor's price for undertaking the work and his willingness to accept both controllable and uncontrollable risks (Uff, 1981; Flanagan and Norman (1993). For a contract to be legally enforceable, an agreement should have:

- Legal purpose and form

- Offer and acceptance

- Consideration (financial obligation)

- Competent parties

\section{Types of construction contract}

\section{Traditional construction contracts}

- Based on firm bills of quantities - The client commissions an architect to prepare a design and upon virtual completion of the design, the surveyor prepares a bill of quantities based upon the architect93). For a contract to be legally enforceable, contractors are invited to price the bill and submit tenders in competition for carrying out the work. The contractor submitting the lowest tender is usually awarded the contract. Such a contract is a lump sum contract (sometimes called a fixed price contract) because a price is stated in the contract as payment for the work described in the bill.

- Based on bills of approximate quantities - This contract is largely similar to the preceding one, except that the quantities given in the bill are approximate only and are subject to later adjustment.

- Based on drawings and specifications - In this type of construction contract no bills of quantities are supplied to tenderers, who have to prepare their own quantities from the drawings provided. This procedure is intended for use in relatively small works ( $£ 50000$ $£ 100000$ which is about ZAR 611,025 - ZAR 1,222,050) and for subcontract works.

- Based on a schedule of rates

a) Standard schedule - A standard schedule lists under appropriate trade headings all the items likely to arise in any construction project, with a unit rate against each item, such as: building works, mechanical services, electrical services, painting and decorating, landscape management, road works.

b) 'Ad hoc' schedule - This is a schedule specifically prepared for a particular project and lists only those items which are appropriate to that project, including any special or unusual items. 
JCPMI Vol. 1 (1): 1 - 26, (November) 2012

- Based on cost reimbursements

a) Cost plus percentage fee - The contractor is paid the prime cost + a fee equal to an agreed percentage of the prime costs of labour, materials and plant used in carrying out the work.

b) Cost plus fixed fee - Under this variant, the fee paid to the contractor is a fixed sum which normally does not vary with the total prime cost, but is based on an estimate of the likely total.

c) Target cost - As an incentive to reducing the total prime cost, the agreement provides for a bonus to be paid to the contractor if the total cost is less than an agreed sum (the 'target') and also a penalty to be paid by him if the total cost exceeds that sum.

\section{Alternatives: (non-traditional) construction contracts}

- Design and build - The contractor is responsible for the design, planning, organisation and control of the construction and for generally satisfying the clientss than an agreed sum (the 'target') and also ainclusive sum.

- Management fee

a) Management contracting - The principal characteristic of management contracting is that the management contractor does none of the construction work himself but it is divided up into work packages which are subcontracted to works contractors, each of whom enters into a contract with the management contractor.

b) Construction management - Construction management is similar to management contracting to the extent that it is a professional consultant service to the client, provided on a fee basis, with the design and construction services being provided by other organisations (Cartlidge, 2009).

Herewith the reasons why many building owners and developers consider the traditional procedures to be no longer satisfactory:

1. The rapidly increasing cost of construction means that large sums of money have to be borrowed to finance projects.

2. Global high interest rates mean that the time occupied by the traditional procedures results in substantial increases in construction cost. These reasons are from a global perspective.

3. Clients are becoming more knowledgeable on construction matters and are demanding better value for money and an earlier return on their investment.

4. High-technology installations require a higher quality of construction. 
JCPMI Vol. 1 (1): 1 - 26, (November) 2012

\section{The JBCC BUILDING AGREEMENTS}

In 1984 the Joint Building Contracts Committee (JBCC) was established to draft an agreement for the construction industry. In 1991 the committee published the JBCC Principal Building Agreement and associated documents. In 1998 the contract was re-examined and re-drafted and a new set of documents, designated JBCC Series 2000, was published (Finsen, 1999). The JBCC is a committee which represents the variety of interests in the construction industry. It has six constituent member organisations which are: the Association of South African Quantity Surveyors; the Institute of South African Architects; the South African Association of Consulting Engineers; the South African

Property Owners' Association; the Specialist Engineering Contractors Committee; and the Building Industries Federation of South Africa (BIFSA) (Van Deventer, 1993). The JBCC Series 2000 is a suite of documents that comprises the Principal Building Agreement, the Nominated/Selected Subcontract Agreement and the Preliminaries, which together constitute the terms and conditions of the agreement between the parties. In addition, there are sundry ancillary documents that do not add to the rights and obligations of the parties but merely facilitate the administration of the contract. These include the Contract Price Adjustment Provisions, the Construction Guarantee, the Payment Guarantee, the Payment Certificate, the Completion Certificate, etc. These documents are intended to be used in conjunction with each other (Finsen, 1999).

\section{Obligations of the employer under the Principal Agreement}

The prime obligations of the employer under the contract according to Finsen (1999), Edwards (1995) and Van Deventer (1993) are:

a) Appoint agents - The employer surrenders many of his contractual rights to his principal agent: inter alia, the right to approve work, to order additional work, to determine the value of variations, to extend the construction, and to determine the amounts of payments to be made under an interim or final payment certificate.

b) Hand over the site to the contractor - At the commencement of the construction period, the site is required to be 'handed over' to the contractor to enable him to carry out the contract. The contractor is put in possession of the site, but ownership of the site remains with the employer.

c) Make payments in accordance with the agreement. 


\section{JCPMI Vol. 1 (1): 1 - 26, (November) 2012}

d) Provide a payment guarantee if required.

e) Provide drawings and instruction - The contractor has undertaken to carry out the work in accordance with the drawings and instructions issued from time to time by the principal agent.

f) Interim payments - No contractor has the financial resources to finance the construction of a project from start to finish, and it has become the invariable custom that the contractor is paid at regular intervals, usually monthly, an amount which represents the value of work done since the previous payment.

g) Final account and final payment - The final account, which represents the contract value at the time that the contractor has finally discharged his contractual obligations, is required to be prepared by the principal agent and submitted to the contractor within 90 working days from the date of practical completion. The contractor is required to co-operate and assist in the preparation of the final account by providing all necessary documents and information that may be requested.

\section{Obligations of the contractor under the Principal Building Agreement}

The obligations of the contractor under the Principal Building Agreement are:

1. Submission of priced bills of quantities or lump-sum document.

2. The bills of quantities will be used primarily for valuing variations, but also for valuing work in progress for interim payment certificates.

3. Furnishing of security - Clause 14.0 provides for three alternative forms of security for the due performance of the contract to be furnished by the contractor, and the choice rests with the contractor, who is required to indicate his choice in his tender. In the event that the contractor fails to provide a security, the employer may either accept the default form of security provided or cancel the agreement.

4. Furnishing waiver of lien - Where the contractor is required to waive his lien, he shall do so, using the JBCC Waiver of Contractor's Lien form, within seven calendar days of receiving a payment guarantee from the employer.

5. Appoint a site representative - Clause 6.0 requires the contractor to have on site at all times a competent representative to administer and control the works. 
JCPMI Vol. 1 (1): 1 - 26, (November) 2012

6. Prepare a construction programme - The common-law position is that the contractor, having contracted to carry out certain work within an agreed time, is free to carry it out in whatever manner he wishes.

7. Carry out and complete the work by the agreed date - The contractor's first and most obvious obligation is to carry out the agreed work, and to do so by the agreed date. Failure to complete the works by the agreed date renders him liable to penalties for non-completion

8. Materials and workmanship to be satisfactory - The contractor is deemed to be an expert in building, and is expected to ensure that the materials that he acquires for the works are not defective.

9. Contractor's obligations to subcontractors - The contractor stands in the same relationship to a subcontractor under a Subcontract Agreement as the employer does to him under the Principal Agreement, to give the subcontractor access to the portion of works necessary for the execution of the subcontract, to make payments, to furnish a payment guarantee, and to provide drawings and instructions.

10. Limitation to liability for latent defects - The contractor's obligation is to complete the works free of patent defects. Latent defects may become apparent sometime after final completion, and if they were due to some breach of the contract, the contractor would be liable for their rectification. In the JBCC Agreements, as a matter of policy, the contractor's liability for latent defects is contractually limited to five years.

11. Liability for design - Where the design is prepared by an architect or engineer, the contractor's contractual obligation is to build in strict accordance with that design, and any deviation from it would amount to breach of contract.

12. Suspension of the works - The contractor is not entitled to suspend the works for any reason whatsoever.

13. Contract instructions - The employer has the unilateral right to vary the extent and nature of the performance to be rendered by the other party. The other party, the contractor, cannot refuse to carry out the varied obligation, and his only remedies are an adjustment of the price he is entitled to be paid for the performance, and, in appropriate circumstances, an extension of the time in which to make such performance. 
JCPMI Vol. 1 (1): 1 - 26, (November) 2012

\section{RESEARCH SAMPLING}

The aim of sampling was to select a representative and non-biased sample to allow for valid and reliable findings. The list of contractors registered as members of the Master Builders Association, KwaZulu-Natal Chapter was obtained. The KwaZulu-Natal area was chosen due to the accessibility of data as the authors resided there and it was selected as the place where interviews were conducted. This resulted in a sample size of 62 . The authors, then, telephonically contacted all the listed contractors to establish whether or not they utilise the JBCC (PBA) so that the scope of the study could be sent to them and to obtain the contact details of the designated person to in order to ensure a satisfactory response rate. Out of the 62 contractors contacted, 23 respondents confirmed that they do in fact use the JBCC (PBA). The researchers thereafter contacted all 23 companies but 4 of them responded by saying that they were too busy to assist. Out of the 19 remaining companies contacted, 9 respondents agreed to be interviewed, providing a response rate of $47 \%$.

\section{Research reliability and validity}

Because of their importance, the reliability and validity of the framework was escalated through increasing the reliability and validity of the research methods and by escalating the reliability and validity of the findings of the research.

In order to increase the reliability and validity of the interview:

- Content validity was ensured by guaranteeing that the interview represents the underlying concept of the study topic

- Contacting the construction industry specialists to assess and evaluate the developed framework

- Selecting a representative and non-biased sample

- Designing the questions to be easy to read, understand and answer

- Coding all closed questions and checking all open questions for themes and patterns before summarising the responses

- Ensuring the confidentiality of interviewees' responses and using the information provided for academic research purposes only 
JCPMI Vol. 1 (1): 1 - 26, (November) 2012

\section{BRIEF DESCRIPTION OF THE IDENTIFICATION, QUANTIFICATION AND CLASSIFICATION FRAMEWORK}

Because of the uncertainty of the future, most business decisions are based on expectations and forecasts. Inevitably, making decisions on these bases involves taking risks. If not managed, these risks will affect the project success and lead to disputes and adversarial relationships. Therefore, contractors have to be aware of their obligations and the risks associated with their contracts (Smith, 1998). The aim of this framework is to enable contractors to identify, quantify and classify the risks associated with the Joint Building Contractors Committee Principal Building Agreement Series 2000 (JBCC PBA).

\section{Identification of the JBCC (PBA) risks}

In order to establish the criteria used to state the risks associated with JBCC (PBA) clauses, it is essential to initiate a link between risks and the factors that lead to organisations' success or failure. The SWOT analysis, a strategic planning tool used to evaluate the strengths, weaknesses, opportunities, and threats involved in a project or in a business venture, was used for audit and analysis of the overall strategic position of each company and its environment, in order to determine risk identification criteria. Businesses of all sizes and types run SWOT analyses to examine the internal working environment of a company and the external market in which that company operates. Strengths and weaknesses are internal factors, while opportunities and threats are external factors (Shutt, 2007). Within this research, the criteria established to identify the risks associated with the JBCC (PBA) from the contractor's perspective are:

- Reducing organisations' strengths

- Increasing organisations' weaknesses

- Reducing organisations' opportunities

- Increasing organisations' threats (Othman and Harinarain, 2009) 
JCPMI Vol. 1 (1): 1 - 26, (November) 2012

\section{Quantification of the JBCC (PBA) risks}

After the identification criteria are established, the next step of the framework development was to quantify the risk associated with the JBCC (PBA) clauses from the contractor's perspective to identify the most important factors that influence contractors' risks. Risks will be quantified based on the probability of occurrence $(p)$ and its severity $(s)$, where the result is $\left(R=p^{*} s\right)$ where $R$ is the measure of risk). This quantification was carried out through an interview with a selected number of managers of construction companies. The 5-point Likert scale was used to quantify the probability and severity of these risks. The numerical scores from the interview provided an indication of the varying degree of influence that each risk had on the contractor. To further investigate the data, a Relative Importance Index (RII) was used to rank the risks according to their influences (Olomolaiye et al., 1987). The calculation was carried out using the following formula:

$$
\text { relative importance index (RII) }=\sum w / A N
$$

where:

$$
\begin{aligned}
\mathrm{w}= & \text { weighting given to each clause by the respondents and range from } 1 \text { to } 5, \\
& \text { where } 1=\text { very low probability or severity and } 5=\text { very high influence }
\end{aligned}
$$

The RII ranges from zero to one. The full list of risk identification criteria and ranking of clauses are provided in Table 2 which shows that some clauses have very high influences of risk to the contractor while others do not. Due to the fact that some clauses have similar RIIs, for example Clauses 25 and 27, a sequential ranking had to be presented as numbers in brackets in the 'rank' column.

\section{Classification of the JBCC (PBA) risks}

The last step of the framework was the classification of the identified and quantified risks. Classifying risks enables the contractor to consider them within a more coherent framework, which provides the construction professionals, in general, and the contractors, in particular, with a more uniform risk language, specifically in fields where risk needs to be communicated to a wide variety 
JCPMI Vol. 1 (1): 1 - 26, (November) 2012

of project stakeholders. It allows one to establish a common understanding of different risks, and provides an essential basis for effective knowledge transfer, within an organisation and from one project to another (Edwards and Bowen, 2005).

In order to be in line with the internal and external perspective adopted in developing the risk identification criteria, this research classifies risks that affect the contractor as internal risks and external risks:

- Internal risks are those which emerge from within the contractor's organisation or those risks that are within the control of the team members, and

- External risks are those which emerge from outside the contractor's organisation, or those risks that are out of the control of the contractor.

The developed framework was sent out to the contractors to obtain their feedback, suggestions for improvement and to ensure its compatibility with the industry standards and requirements. Their feedback was then considered and the criteria were revised accordingly. The updated criteria were then used in an interview process to apply the framework, see Table 1.

Table 1

The Identification, Quantification and Classification Framework (IQCF)

\begin{tabular}{|c|c|c|c|c|c|c|c|c|c|}
\hline JBCC (PBA) & \multicolumn{4}{|c|}{ Risk identification criteria } & \multicolumn{3}{|c|}{ Risk quantification } & \multicolumn{2}{|c|}{ Risk classification } \\
\hline & 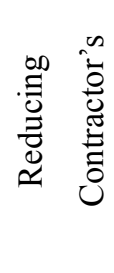 & 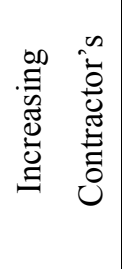 & 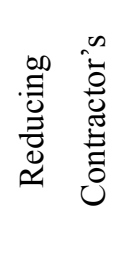 & 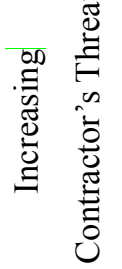 & 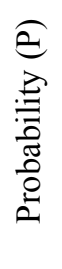 & 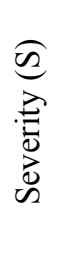 & 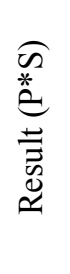 & 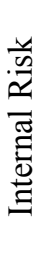 & 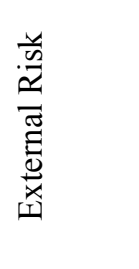 \\
\hline Clause 1 & & & & & & & & & \\
\hline Clause $\mathrm{n}$ & & & & & & & & & \\
\hline
\end{tabular}

Source: Harinarain and Othman, 2007 
JCPMI Vol. 1 (1): 1 - 26, (November) 2012

\section{ANALYSIS OF CONTRACTORS' RESPONSES TO EVALUATION AND APPLICATION OF THE FRAMEWORK}

Interviews were carried out with 9 construction companies, providing a response rate of $47 \%$. According to Babbies (1992) as a rule of thumb 50\% is adequate while Mcneil and Chapman (2005); Saunders et al. (2003); Gillham (2000); Tashakkori and Teddlie (1998) and Fellows and Liu (1997) state that $30 \%$ to $40 \%$ is acceptable because of the fact that few people are likely to participate in surveys.

Both quantitative and qualitative data analysis approaches were applied to interpret the data collected from the interviews. Quantitative analysis was used to assess closed-ended questions using Microsoft Excel spreadsheets by utilising tables and graphs. Qualitative analysis was employed to analyse open-ended questions in order to gain an understanding from the respondents' point of view. Although the firms identify risks in the JBCC when tendering, they do not do this often enough because it is too time-consuming and there is a lack of training.

\section{Analysis of contractors' risk identification}

The respondents were asked to identify risks according to 4 categories, namely the risk could reduce the company's strengths, increase the company's weaknesses, reduce its opportunities, or increase its threats. All the respondents stated that C40 (Dispute settlement) and C17 (Contract instructions) fall under all the risk identification criteria. Disputes are considered a risk to the contractor because they can reduce a company's strength due to the fact that they can be a long drawn-out process which involves key personnel. In addition, disputes could increase the company's weakness because of the time, cost and resources involved. Furthermore, disputes reduce a company's opportunities because the company might get a bad name and because of the capital that is tied up. Finally, disputes increase the company's threats by reducing the number of potential new jobs as clients would not want to hire a contractor that they believe will rush into a dispute.

Although contractors are compensated for work carried out in terms of contract instructions, contractors still consider contract instructions to be risky because they can reduce a company's 
JCPMI Vol. 1 (1): 1 - 26, (November) 2012

strength due to the time, cost, quality and resources that are tied up. In addition, they increase a company's weakness by gaining a poor reputation should the company fail to carry out the instructions as required. Furthermore, contract instructions reduce a company's opportunities by making it unable to free up resources for other jobs. Finally, they increase threats because a poor reputation will lead to a lack of new opportunities.

C29 (Revision to date for practical completion) and C30 (Penalty) were seen by the respondents as totally affecting a company's strength because an extension of time means that the resources (both manpower and plant) are not available for other jobs and new projects, even though they are compensated for an extension due to delay of a controlling work item. By paying the hefty penalties that clients are now insisting on, the company can slip into a negative cash-flow situation.

C20 (Nominated subcontractors) and C21 (Selected subcontractors) were seen by the respondents as totally increasing a company's weakness because of their negative impact on the main contractor's performance due to their non-compliance to job requirements and delay in completing their jobs as specified. Even though the main contractor will be granted an extension of time if the nominated subcontractor defaults, it will still mean he has to wait for completion of the job and the main contractor is still ultimately liable for the quality of the work. Selected subcontractors pose an even bigger risk due to the fact that the main contractor is part of the selection process and there is very little recourse available to him should the subcontractor default.

C4 (Design responsibility) was seen by the respondents as totally reducing a company's opportunities because contractors felt that they could have a valuable input into the design process in terms of constructability. Although the contractors liked the fact that they were not responsible for the architects/engineers design, they could have a good opportunity to improve their performance and produce a better product if their feedback is reflected in the design decision-making process. $\mathrm{C} 7$ (Regulations), C15 (Works execution) and C31 (Interim payment) were seen by the respondents as totally increasing a company's threats. The contractor could face serious problems should the bylaws, regulations and laws of the local or other authorities suddenly change. The execution and completion of work are at risk if the employer does not hand over the site on time. The contractor's 
JCPMI Vol. 1 (1): 1 - 26, (November) 2012

cash flow is at great risk when the interim payments are delayed. It can be seen that these threats are external to the contractor.

The effects of the remaining clauses on contractor's strengths, weaknesses, opportunities and threats are depicted in Table 2. All respondents considered the method developed to identify risks as acceptable with a rating of $67 \%$ (very good), while $33 \%$ gave it a rating of good. None of the respondents made any suggestions as to how this part of the framework could be improved.

Table 2

Risk identification criteria

\begin{tabular}{|c|c|c|c|c|c|}
\hline \multicolumn{6}{|c|}{ RISK IDENTIFICATION CRITERIA } \\
\hline & CLAUSES & 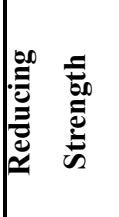 & 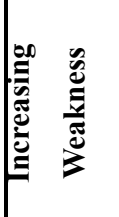 & 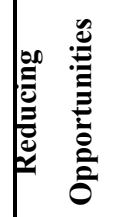 & 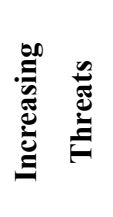 \\
\hline 40.0 & DISPUTE SETTLEMENT & \multicolumn{4}{|c|}{$100 \%$} \\
\hline 17.0 & CONTRACT INSTRUCTIONS & \multicolumn{4}{|c|}{$100 \%$} \\
\hline 29.0 & REVISION OF DATE FOR PRACTICAL COMPLETION & $100 \%$ & & & \\
\hline 30.0 & PENALTY & $100 \%$ & & & \\
\hline 20.0 & NOMINATED SUBCONTRACTORS & & $100 \%$ & & \\
\hline 21.0 & SELECTED SUBCONTRACTORS & & $100 \%$ & & \\
\hline 4.0 & DESIGN RESPONSIBILITY & & & $100 \%$ & \\
\hline 7.0 & REGULATIONS & & & & $100 \%$ \\
\hline 15.0 & WORKS EXECUTION & & & & $100 \%$ \\
\hline 31.0 & INTERIM PAYMENT & & & & $100 \%$ \\
\hline 16.0 & ACCESS TO THE WORKS & $50 \%$ & $50 \%$ & & \\
\hline 18.0 & SETTING OUT OF THE WORKS & $50 \%$ & $50 \%$ & & \\
\hline 33.0 & RECOVERY OF EXPENSE AND LOSS & $50 \%$ & $50 \%$ & & \\
\hline 34.0 & FINAL ACCOUNT AND FINAL PAYMENT & $50 \%$ & $50 \%$ & & \\
\hline 10.0 & GENERAL INSURANCES & $50 \%$ & & & $50 \%$ \\
\hline 11.0 & SPECIAL INSURANCES & $50 \%$ & & & $50 \%$ \\
\hline 12.0 & EFFECTING INSURANCES & $50 \%$ & & & $50 \%$ \\
\hline 22.0 & DIRECT CONTRACTORS & $50 \%$ & & & $50 \%$ \\
\hline
\end{tabular}


JCPMI Vol. 1 (1): 1 - 26, (November) 2012

\begin{tabular}{|l|l|c|c|c|c|}
\hline 32.0 & ADJUSTMENT TO THE CONTRACT VALUE & $50 \%$ & & & $50 \%$ \\
\hline 6.0 & SITE REPRESENTATIVE & & $50 \%$ & $50 \%$ & \\
\hline 23.0 & DOMESTIC SUBCONTRACTORS & & $50 \%$ & $50 \%$ & \\
\hline 28.0 & SECTIONAL COMPLETION & & $50 \%$ & $50 \%$ & \\
\hline 35.0 & PAYMENT TO OTHER PARTIES & $50 \%$ & $50 \%$ & \\
\hline 5.0 & EMPLOYER'S AGENTS & $50 \%$ & & $50 \%$ \\
\hline 36.0 & TERMINATION - EMPLOYER - CONTRACTOR'S DEFAULT & & $50 \%$ & & $50 \%$ \\
\hline 9.0 & INDEMNITIES & & & $50 \%$ & $50 \%$ \\
\hline 13.0 & ASSIGNMENT & & & $50 \%$ & $50 \%$ \\
\hline 19.0 & TEMPORARY WORKS \& PLANT & & & $50 \%$ & $50 \%$ \\
\hline 24.0 & PRACTICAL COMPLETION & & & $50 \%$ & $50 \%$ \\
\hline 25.0 & WORKS COMPLETION & & & $50 \%$ & $50 \%$ \\
\hline 26.0 & FINAL COMPLETION & & & $50 \%$ & $50 \%$ \\
\hline 37.0 & CANCELLATION BY EMPLOYER-LOSS \& DAMAGE & & & $50 \%$ & $50 \%$ \\
\hline 39.0 & CANCELLATION-CESSATION OF WORKS & $25 \%$ & $50 \%$ & $25 \%$ & \\
\hline 27.0 & LATENT DEFECTS & $25 \%$ & $50 \%$ & & $25 \%$ \\
\hline 3.0 & DOCUMENTS & $25 \%$ & & $50 \%$ & $25 \%$ \\
\hline 38.0 & CANCELLATION - EMPLOYER'S DEFAULT & & $25 \%$ & $50 \%$ & $25 \%$ \\
\hline 8.0 & WORKS RISK & N/A & \\
\hline 14.0 & SECURITY & & N/A & $50 \%$ \\
\hline 1.0 & DEFINITIONS & & & $50 \%$ \\
\hline 2.0 & OFFER, ACCEPTANCE AND PERFORMANCE & & $50 \%$ \\
\hline
\end{tabular}

Source: Harinarain, 2008

\section{Analysis of contractors' risk quantification}

In order to accurately quantify risks, it is broken down into 2 categories, namely the probability of the risks occurring and the severity of the risk. By multiplying the probability and severity the quantification was obtained. The maximum quantification that could be achieved is 25 .

A two-stage approach was utilised for quantitative data analysis in this research. The first stage involved the measure of the central tendency to obtain an overview of the typical value for each variable by calculating the mean, median and mode of the frequency distribution. The second stage 
JCPMI Vol. 1 (1): 1 - 26, (November) 2012

involved the use of the Relative Importance Index as all the clauses in the JBCC (PBA) do not have the same influence on the contractor.

C17 (Contract instructions) had the highest result of 20 out of 25 . The respondents mentioned that this clause had the highest probability of occurrence (with a mean of 4.5, median of 4.5 and mode of 4) and the greatest severity (with a mean of 4.5 , median of 4.5 and mode of 4 ) once it occurs. Contract instructions affect the projects' duration, cost and sometimes even quality.

C5 (Employer's agents) and C29 (Revision to date of practical completion) had a result of 17. The probability of occurrence for $\mathrm{C} 5$ was 4 (with a mean of 4 , median of 4 and mode of 4 ) and a severity of 4.3 (with a mean of 4.3, median of 4 and mode of 4 ) once it occurs. The probability of occurrence for $\mathrm{C} 29$ was 4.3 (with a mean of 4.3, median of 4.5 and mode of 5) and a severity of 4 (with a mean of 4 , median of 4 and mode of 3 ) once it occurs. Poor choice of agents can seriously hinder the project completion and quality, while extensions of time require resources that the contractors felt could be utilised elsewhere even though they are compensated for due extension.

C25 (Works completion) had the third highest score of 15 . The probability of occurrence for C25 was 3.5 (with a mean of 3.5, median of 3.5 and mode of 3 ) and a severity of 4.3 (with a mean of 4.3, median of 4.5 and mode of 5) once it occurs. The respondents felt that sometimes clients were unreasonable in terms of the site handover date and insisted that damages, whether caused by the contractor or not, were remedied prior to accepting site handover.

The remainder of the responses to this section is represented in Table 3 , and they are rounded off to the nearest whole number. It is noteworthy to mention that the close results of the mean, median and mode indicated the homogeneity of the collected data.

The risk-quantification system employed in the framework was rated as very good by $45 \%$, good by $44 \%$ and average by $11 \%$ of the respondents. The group of respondents who rated the quantification method as average did not, however, provide suggestions on how to improve the framework. 
JCPMI Vol. 1 (1): 1 - 26, (November) 2012

Table 3

Risk quantification criteria

\begin{tabular}{|c|c|c|c|c|c|c|c|c|}
\hline \multicolumn{2}{|r|}{ Risk quantification } & \multicolumn{3}{|c|}{ Probability } & \multicolumn{3}{|c|}{ Severity } & \multirow{2}{*}{$\begin{array}{c}\text { Result } \\
(R) \\
=\left(P^{*} \mathbf{S}\right)\end{array}$} \\
\hline & CLAUSES & Mean & Median & Mode & Mean & Median & Mode & \\
\hline 17.0 & CONTRACT INSTRUCTIONS & 4.5 & 4.5 & 4 & 4.5 & 4.5 & 4 & 20 \\
\hline 5.0 & EMPLOYER'S AGENTS & 4.0 & 4 & 4 & 4.3 & 4 & 4 & 17 \\
\hline 29.0 & $\begin{array}{l}\text { REVISION - DATE FOR PRACTICAL } \\
\text { COMPLETION }\end{array}$ & 4.3 & 4.5 & 5 & 4.0 & 4 & 3 & 17 \\
\hline 25.0 & WORKS COMPLETION & 3.5 & 3.5 & 3 & 4.3 & 4.5 & 5 & 15 \\
\hline 3.0 & DOCUMENTS & 3.5 & 3 & 3 & 4.0 & 4 & 4 & 14 \\
\hline 27.0 & LATENT DEFECTS & 3.5 & 4 & 4 & 4.0 & 4 & 4 & 14 \\
\hline 24.0 & PRACTICAL COMPLETION & 3.3 & 3.5 & 4 & 4.0 & 4 & 4 & 13 \\
\hline 26.0 & FINAL COMPLETION & 3.3 & 3.5 & 4 & 3.8 & 4 & 4 & 12 \\
\hline 30.0 & PENALTY & 3.3 & 3.5 & 4 & 3.8 & 4 & 4 & 12 \\
\hline 14.0 & SECURITY & 3.3 & 3 & 2 & 3.3 & 3 & 2 & 11 \\
\hline 23.0 & DOMESTIC SUBCONTRACTORS & 3.3 & 3 & 2 & 3.3 & 3 & 2 & 11 \\
\hline 32.0 & ADJUSTMENT TO THE CONTRACT VALUE & 3.5 & 3.5 & 3 & 3.0 & 3 & 3 & 11 \\
\hline 34.0 & $\begin{array}{l}\text { FINAL ACCOUNT AND FINAL PAYMENT } \\
\end{array}$ & 3.0 & 3.5 & 4 & 3.8 & 4 & 4 & 11 \\
\hline 21.0 & SELECTED SUBCONTRACTORS & 2.8 & 2.5 & 2 & 3.3 & 3.5 & 4 & 9 \\
\hline 22.0 & DIRECT CONTRACTORS & 3.0 & 2.5 & 2 & 3.0 & 2.5 & 2 & 9 \\
\hline 40.0 & DISPUTE SETTLEMENT & 2.8 & 3 & 3 & 3.3 & 3 & 3 & 9 \\
\hline 28.0 & SECTIONAL COMPLETION & 2.8 & 2.5 & 2 & 2.8 & 2.5 & 2 & 8 \\
\hline 31.0 & INTERIM PAYMENT & 2.5 & 2.5 & 3 & 3.3 & 3 & 3 & 8 \\
\hline 35.0 & PAYMENT TO OTHER PARTIES & 2.8 & 2.5 & 2 & 2.8 & 2.5 & 2 & 8 \\
\hline 38.0 & CANCELLATION - EMPLOYER'S DEFAULT & 2.5 & 2 & 2 & 3.3 & 3 & 2 & 8 \\
\hline 10.0 & GENERAL INSURANCES & 2.3 & 2.5 & 3 & 3.3 & 3 & 3 & 7 \\
\hline 11.0 & SPECIAL INSURANCES & 2.3 & 2.5 & 3 & 3.3 & 3 & 3 & 7 \\
\hline 15.0 & WORKS EXECUTION & 2.3 & 2 & 2 & 3.0 & 3 & 3 & 7 \\
\hline 37.0 & CANCELLATION - LOSS AND DAMAGE & 2.3 & 2 & 2 & 3.0 & 2.5 & 2 & 7 \\
\hline 8.0 & WORKS RISK & 2.3 & 2.5 & 3 & 2.8 & 3 & 3 & 6 \\
\hline 9.0 & INDEMNITIES & 2.0 & 2 & 2 & 3.0 & 2.5 & 2 & 6 \\
\hline 12.0 & EFFECTING INSURANCES & 2.0 & 2 & 2 & 3.0 & 2.5 & 2 & 6 \\
\hline 20.0 & NOMINATED SUBCONTRACTORS & 2.3 & 2 & 2 & 2.8 & 2.5 & 2 & 6 \\
\hline 36.0 & TERMINATION - CONTRACTOR'S DEFAULT & 2.0 & 2 & 2 & 2.8 & 2.5 & 3 & 6 \\
\hline 7.0 & REGULATIONS & 1.8 & 2 & 2 & 2.8 & 2 & 2 & 5 \\
\hline 18.0 & SETTING OUT OF THE WORKS & 2.3 & 2.5 & 3 & 2.3 & 2.5 & 3 & 5 \\
\hline 33.0 & RECOVERY OF EXPENSE AND LOSS & 2.3 & 2.5 & 3 & 2.3 & 2.5 & 3 & 5 \\
\hline 39.0 & CANCELLATION-CESSATION OF WORKS & 1.8 & 2 & 2 & 2.5 & 2 & 2 & 4 \\
\hline 16.0 & ACCESS TO THE WORKS & 1.8 & 2 & 2 & 1.8 & 2 & 2 & 3 \\
\hline 4.0 & DESIGN RESPONSIBILITY & 1.3 & 1 & 1 & 1.3 & 1 & 1 & 2 \\
\hline 6.0 & SITE REPRESENTATIVE & 1.3 & 1 & 1 & 1.3 & 1 & 1 & 2 \\
\hline 13.0 & ASSIGNMENT & 1.3 & 1 & 1 & 1.5 & 1.5 & 2 & 2 \\
\hline 19.0 & TEMPORARY WORKS \& PLANT & 1.3 & 1 & 1 & 1.5 & 1.5 & 2 & 2 \\
\hline 1.0 & DEFINITIONS & & N/A & & & N/A & & $\mathbf{0}$ \\
\hline 2.0 & OFFER, ACCEPTANCE AND PERFORMANCE & & N/A & & & N/A & & $\mathbf{0}$ \\
\hline
\end{tabular}

Source: Harinarain, 2008 
JCPMI Vol. 1 (1): 1 - 26, (November) 2012

\section{Relative importance of the JBCC (PBA) clauses}

To allow for further analysis of the data, a relative importance index (RII) was utilised to rank the clauses according to their influences. Investigation of the results showed that the clauses could be classified into three categories as shown in Table 4 and Figure 2. The first category contains clauses with a very high influence with an RII of above 0.70 . This includes C17 (Contract instructions), C29 (Revision of date for practical completion), C5 (Employers agents), C27 (Latent defects), C25 (Works completion) and C3 (Documents).

The second category contains clauses with an average to high influence, with RII's lying between (0.45) and (0.70). This includes C30 (Penalty), C26 (Final completion), C24 (Practical completion), C23 (Domestic subcontractors), C14 (Security), C34 (Final account and final payment), C22 (Direct contractors), C40 (Dispute settlement), C35 (Payment to other parties), C28 (Sectional completion), C21 (Selected subcontractors), C38 (Cancellation by contractor - employer's default), C31 (Interim payment), C37 (Cancellation by employer- Loss and damage), C33 (Recovery of expense and loss), C20 (Nominated subcontractors), C18 (Setting out of the works), C15 (Works execution), C11 (Liability insurances), $\mathrm{C} \mathbf{1 0}$ (Works insurances) and C8 (Works risk).

The final category contains clauses with very low to low influences, with RIIs of less than 0.45 . This includes C36 (Cancellation - contractor's default), C12 (Effecting insurances), C16 (Access to the works), C7 (Regulations), C32 (Adjustment to the contract value), C39 (Cancellation-cessation of works0, C19 (Temporary works \& plant), C13 (Assignment), C9 (Indemnities), C6 (Site representative), C4 (Design responsibility), C1 (Definitions), C2 (Offer, acceptance and performance). Sixty seven percent of the respondents rated the risk classification system applied in the framework as very good while $33 \%$ rated it as good. Suggestions for further improvement were not made by any of the respondents. 
JCPMI Vol. 1 (1): 1 - 26, (November) 2012

Table 4

Relative Importance Index (RII) of the risks associated with the JBCC (PBA) clauses

\begin{tabular}{|c|c|c|c|c|}
\hline \multicolumn{5}{|c|}{ Risk quantification } \\
\hline & CLAUSES & RII & Rank & \\
\hline 17.0 & CONTRACT INSTRUCTIONS & 0.90 & 1 & [1] \\
\hline 29.0 & REVISION OF DATE FOR PRACTICAL COMPLETION & 0.85 & 2 & {$[2]$} \\
\hline 5.0 & EMPLOYER'S AGENTS & 0.80 & 3 & {$[3]$} \\
\hline 27.0 & LATENT DEFECTS & 0.70 & 4 & [4] \\
\hline 25.0 & WORKS COMPLETION & 0.70 & 4 & {$[5]$} \\
\hline 3.0 & DOCUMENTS & 0.70 & 4 & {$[6]$} \\
\hline 30.0 & PENALTY & 0.65 & 5 & {$[7]$} \\
\hline 26.0 & FINAL COMPLETION & 0.65 & 5 & {$[8]$} \\
\hline 24.0 & PRACTICAL COMPLETION & 0.65 & 5 & [9] \\
\hline 23.0 & DOMESTIC SUBCONTRACTORS & 0.65 & 5 & {$[10]$} \\
\hline 14.0 & SECURITY & 0.65 & 5 & [11] \\
\hline 34.0 & FINAL ACCOUNT AND FINAL PAYMENT & 0.60 & 6 & {$[12]$} \\
\hline 22.0 & DIRECT CONTRACTORS & 0.60 & 6 & [13] \\
\hline 40.0 & DISPUTE SETTLEMENT & 0.55 & 7 & {$[14]$} \\
\hline 35.0 & PAYMENT TO OTHER PARTIES & 0.55 & 7 & {$[15]$} \\
\hline 28.0 & SECTIONAL COMPLETION & 0.55 & 7 & {$[16]$} \\
\hline 21.0 & SELECTED SUBCONTRACTORS & 0.55 & 7 & {$[17]$} \\
\hline 38.0 & CANCELLATION - EMPLOYER'S DEFAULT & 0.50 & 8 & [18] \\
\hline 31.0 & INTERIM PAYMENT & 0.50 & 8 & [19] \\
\hline 37.0 & CANCELLATION BY EMPLOYER. LOSS AND DAMAGE & 0.45 & 9 & {$[20]$} \\
\hline 33.0 & RECOVERY OF EXPENSE AND LOSS & 0.45 & 9 & {$[21]$} \\
\hline 20.0 & NOMINATED SUBCONTRACTORS & 0.45 & 9 & {$[22]$} \\
\hline 18.0 & SETTING OUT OF THE WORKS & 0.45 & 9 & {$[23]$} \\
\hline 15.0 & WORKS EXECUTION & 0.45 & 9 & {$[24]$} \\
\hline 11.0 & SPECIAL INSURANCES & 0.45 & 9 & {$[25]$} \\
\hline 10.0 & GENERAL INSURANCES & 0.45 & 9 & {$[26]$} \\
\hline 8.0 & WORKS RISK & 0.45 & 9 & {$[27]$} \\
\hline 36.0 & TERMINATION BY EMPLOYER - CONTRACTOR'S DEFAULT & 0.40 & 10 & [28] \\
\hline 12.0 & EFFECTING INSURANCES & 0.40 & 10 & [29] \\
\hline 16.0 & ACCESS TO THE WORKS & 0.35 & 11 & [30] \\
\hline
\end{tabular}


JCPMI Vol. 1 (1): 1 - 26, (November) 2012

\begin{tabular}{|c|l|c|c|c|}
\hline 7.0 & REGULATIONS & 0.35 & 11 & {$[31]$} \\
\hline 32.0 & ADJUSTMENT TO THE CONTRACT VALUE & 0.35 & 11 & {$[32]$} \\
\hline 39.0 & CANCELLATION-CESSATION OF WORKS & 0.35 & 11 & {$[33]$} \\
\hline 19.0 & TEMPORARY WORKS \& PLANT & 0.25 & 12 & {$[34]$} \\
\hline 13.0 & ASSIGNMENT & 0.25 & 13 & {$[35]$} \\
\hline 9.0 & INDEMNITIES & 0.25 & 12 & {$[36]$} \\
\hline 6.0 & SITE REPRESENTATIVE & 0.25 & 12 & {$[37]$} \\
\hline 4.0 & DESIGN RESPONSIBILITY & 0.25 & 12 & {$[38]$} \\
\hline 1.0 & DEFINITIONS & 0 & 13 & {$[39]$} \\
\hline 2.0 & OFFER, ACCEPTANCE AND PERFORMANCE & 0 & 13 & {$[40]$} \\
\hline & & & & \\
\hline
\end{tabular}

Source: Harinarain, 2008

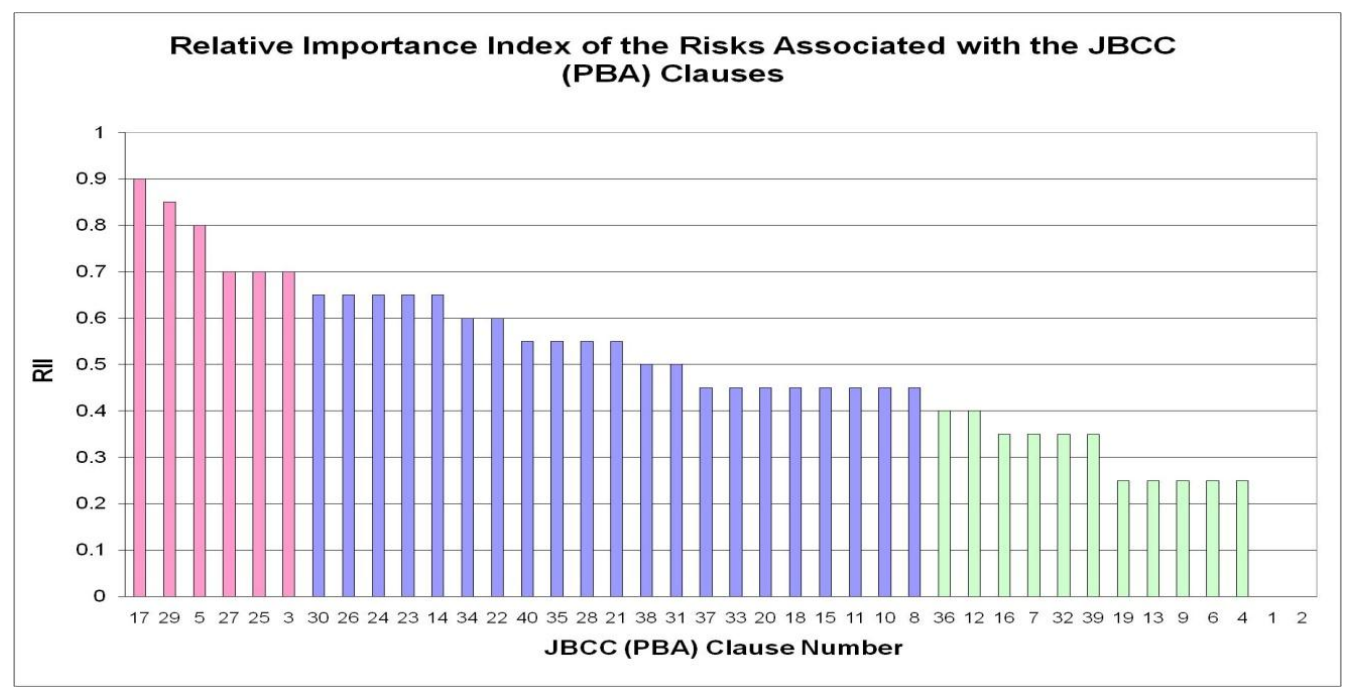

Figure1: Relative Importance Index (RII) of the risks associated with the JBCC (PBA) clauses (Source: Harinarain, 2008)

\section{Analysis of contractors' risk classification}

Risk in this framework was classified as either internal or external. Internal risks are the ones which emerge from within the contractor's organisation, whereas the external risks are the ones which emerge from outside the contractor's organisation. Twenty percent of the risks are internal, that is, they emerge from within the contractor's organisation. 
JCPMI Vol. 1 (1): 1 - 26, (November) 2012

Internal risk clauses are C6 (Site representative), C14 (Security), C15 (Works execution), C18 (Setting out of the works), C21 (Selected subcontractors), C23 (Domestic subcontractors), C27 (Latent defects) and C30 (Penalty).

Twenty three percent of the risks according to the respondents are external, that is, they emerge from outside the contractor's organisation. External risk clauses are, C5 (Employers agents), C7 (Regulations), C20 (Nominated subcontractors), C22 (Direct contractors), C29 (Revision of date for practical completion), C35 (Payment to other parties), C36 (Cancellation - contractor's default), C37 (Cancellation by employer-loss and damage), Clause 38 (Cancellation by contractor - employer's default). Forty nine percent of the risks are classified as both internal and external risks. They are C3 (Documents), C4 (Design responsibility), C8 (Works risk), C9 (Indemnities), C10 (Works insurances), C11 (Liability insurances), C12 (Effecting insurances), C16 (Access to the works), C17 (Contract instructions), C19 (Assignment), C24 (Practical completion), C25 (Works completion), C26 (Final completion), C28 (Sectional completion), C31 (Interim payment), C32 (Adjustment to the contract value), C33 (Recovery of expense and loss), Clause 34 (Final account and final payment), C39 (Cancellation-cessation of works), C40 (Dispute settlement). Five percent of the clauses, namely C1 (Definitions) and C2 (Offer, acceptance and performance), were not analyzed because they contain explanations of various aspects of the contract as depicted in figure (2).

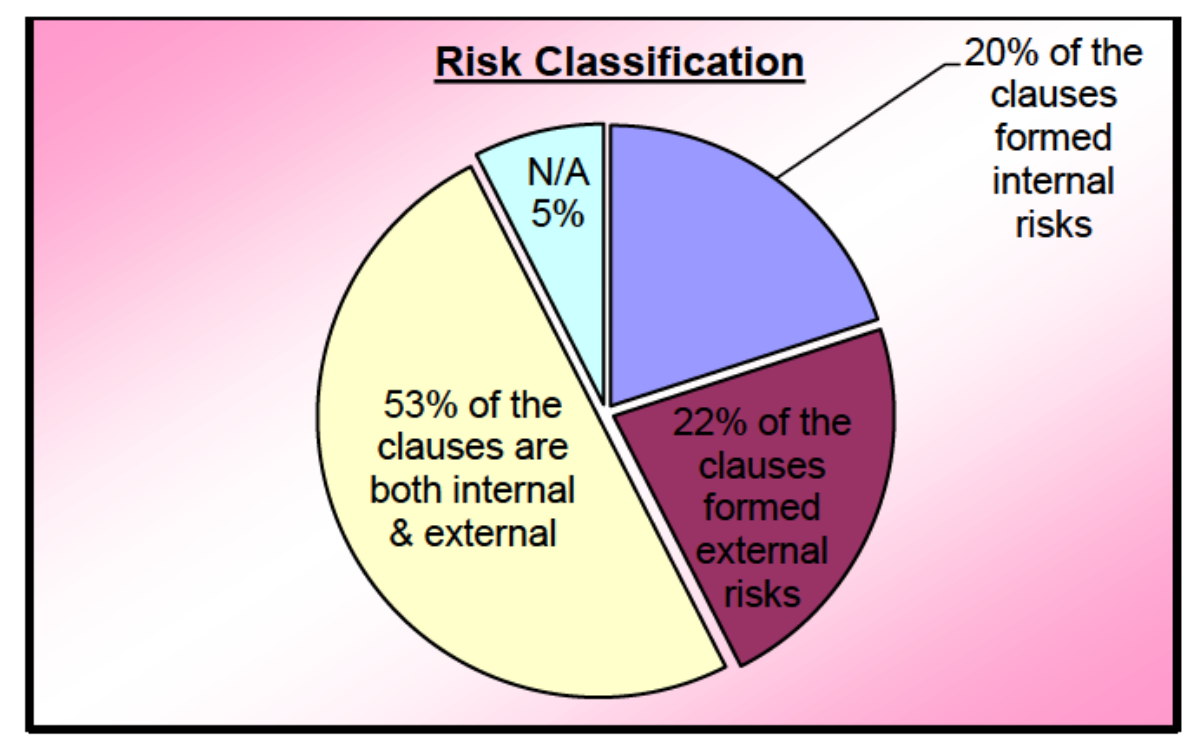

Figure 2: Risk classification analysis (Source: Harinarain, 2008) 
JCPMI Vol. 1 (1): 1 - 26, (November) 2012

\section{CONCLUSIONS AND RECOMMENDATIONS}

Being one of the biggest industries worldwide, the construction industry is subject to more risk than any other industry. This reality highlights the importance of having a proper understanding of the risks associated with construction contracts. Towards addressing this issue, an innovative framework, aimed at identifying, quantifying and classifying the risks associated with the JBCC (Principal Building Agreement) in South Africa, has been developed by the authors. Towards ensuring its validity and reliability, this paper provides an analysis of the contractors' responses and feedback gained through the application of the developed framework.

Most firms admitted that they quantified risk by observing and acknowledging the impact of the clauses on the contract, the preliminaries and general structure, the profitability, duration, the buildability of the project and value engineering and it is believed that the IQCF can greatly assist companies in improving risk quantification. The techniques employed by the respondents to manage risk were contingency measures, meetings, identifying and quantifying risks, probability of occurrence, profiling risks, crisis management and post-tender-value engineering. The use of the IQCF and its detailed analysis aided and assisted in improving current practices in place.

All of the respondents stated that the framework adequately covered all areas of risk when applied. Seventy five percent of the respondents rated the framework as very good, while $25 \%$ rated it as good. All of the respondents believed that the framework could be of benefit to their firms by either assisting junior employees, as an aid in training employees to use the JBCC contract or to fill in and complement their current systems. It was suggested that further studies could include sections on health and safety, quality and cost, which were not included here as they did not fall within the scope of this study. The framework presented to industry was considered to be an innovative and acceptable tool that would fill the gap in managing project risks and complement current practices in terms of risk identification, quantification and classification. 
JCPMI Vol. 1 (1): 1 - 26, (November) 2012

\section{REFERENCES}

Babbies, E. (1992). The practice of social research. Wadsworth Publishing: Belmont, CA.

Cartlidge, D. (2009). Quantity surveyor's pocket book. Butterworth-Heinemann is an imprint of Elsevier Linacre House, Jordan Hill, Oxford OX2 8DP, UK.

Clough, R. (1975). Construction contracting. John Wiley \& Sons: New York.

Edwards, L. (1995). Practical risk management in the construction industry. Telford Publishers: London.

Edwards, P.J. and Bowen, P.A. (2005). Risk management in project organisations. ButterworthHeinemann: Oxford.

Fellows, R. and Liu, A. (1997). Research methods for construction. Blackwell Publisher Ltd.: London.

Finsen, E. 1999. The building contract: a commentary on the JBCC agreements. Spon Press: New York.

Flanagan, R. and Norman, G. (1993). Risk management and construction. Blackwell Scientific Publications: London.

Gillham, B. (2000). Developing a questionnaire. Continuum: London.

Harinarain, N. (2008). Identification, quantification and classification of risks pertaining to building contractors in the JBCC (Principal Building Agreement). M.Sc. Thesis. University of KwaZulu-Natal: South Africa.

Harinarain, N. and Othman, A.A.E. (2007). A framework for identifying, quantifying and classifying risks associated with the Principal Building Agreement in South Africa. In: Proceedings of the 2nd Built Environment Conference, Port Elizabeth, South Africa, 17-19 June, pp. 138-151.

Kometa, S.T. and Olomolaiye, P.O. (1997). Evaluation of factors influencing construction clients' decision to build. Journal of Management in Engineering, ASCE, 3(2): 77-86.

McNeil, P. and Chapman, S. (2005). Research methods. $3^{\text {rd }}$ edition. Routledge: London.

Miles, J.C., Moore, C.J., Kotb, A.S.M. and Hamedani, A.J. (2000). End user evaluation of engineering knowledge based systems. Civil Engineering \& Environmental Systems, 17 (4): 293-317.

$\mathrm{Ng}$, S.T. and Smith, N. (1998). Verification and validation of case-based prequalification systems. Journal of Computing in Civil Engineering, ASCE, 12(4): 215-225.

Olomolaiye, P.O., Price, A.D.F. and Wahab, K.A. (1987). Problems influencing craftsmen's productivity in Nigeria. Build Environment, 22(4): 317-323.

Othman, A.A.E. and Harinarain, N. (2009). Managing risks associated with the JBCC (Principal Building Agreement) from the South African contractor's perspective. Acta Stuctilia, Journal for the Physical and Development Sciences, 16 (1): 83-119.

Ren, Z. (2002). A multi-agent systems approach to construction claims negotiation. Ph.D. Thesis. Loughborough University: UK.

Saunders, M., Lewis, P. and Thornhill, A. (2003). Research methods for business students. Prentice Hall: Harlow. 
JCPMI Vol. 1 (1): 1 - 26, (November) 2012

Sawczuk, B. (1996). Risk avoidance for the building team. Spon: London.

Shutt, C.A. (2007). Assess strengths, weaknesses, opportunities and threats to keep your company focused on success. [Online] Available from: http://forpros.lowes.com (Accessed: 23 April 2011).

Smith, N.J. (1998). Managing risk in construction projects. Blackwell Scientific Publications:

Great Britain.

Tashakkori, A. and Teddlie, C. (1998). Mixed methodology, combining qualitative \& quantitative approaches. Sage Publications: London.

Uff, J. (1981). Construction law: an outline of law and practice relating to the construction industry. Sweet \& Maxwell: London.

Van Deventer, R. (1993). The law of construction contracts.

Chancery Wiley Law Publications: Chichester. John Wiley \& Sons Ltd: Dunfermline. 